\title{
A TRANSMIDIAÇÃO COMO UMA ESCRITA DE RESISTÊNCIA
}

\author{
Andrea Versuti ${ }^{1}$ \\ Daniel David Silva ${ }^{2}$
}

\section{Narrativas transmídia e transmidiação}

Em um cenário em que cada vez mais os conteúdos midiáticos migram para diferentes e sincronizadas interfaces e plataformas, surgem as Narrativas Transmídia. Trata-se de uma forma específica de recontar uma história ou expandi-la, aproveitando as oportunidades e novos elementos em um universo ficcional composto por múltiplas linhas do tempo. Este tipo de narrativa permite a criação de um universo ficcional formado a partir de conteúdos distribuídos em várias plataformas midiáticas, e esta distribuição possibilita a expansão do engajamento das pessoas acerca de tal conteúdo, promovendo uma imersão (JENKINS, 2008) e a liberação do polo de emissão, uma vez que podemos ser também produtores de conteúdos digitais. "Na cultura pós-massiva, que constitui a atual cibercultura, produzir, fazer circular e acessar cada vez mais informação tornam-se atos cotidianos, corriqueiros, banais" (LEMOS, 2009, p. 39).

É fato que vivemos em meio à mudanças substanciais na sociedade contemporânea e, com isso, os meios de comunicação mudaram de forma mais significativa a partir das estruturas "líquidas" da pós-modernidade. Dentre estas mudanças, chamamos a atenção para o advento do conteúdo digitalmente expandido.

Tanto hipertexto, quanto hipermídia, podem ser considerados processos interativos, posto que nos permitem escolher o melhor caminho para alcançar novas experiências, de acordo com seus desejos pessoais. Esses ambientes são líquidos, participativos, fluidos, autônomos, e corroborando as perspectivas de Santaella (1996) e Bauman (2003) permitem uma leitura sem começo, meio ou fim, oferecendo-nos a possibilidade de "olhar para" o conteúdo através de diferentes caminhos. Em seguida, a narrativa presente no hipertexto é definida como um modo de leitura livre, no qual a forma de leitura não é linear, mas determinada pelos interesses dos leitores.

A hipertextualidade é um dos processos interativos mais evidentes nas narrativas transmídias. No entanto, a maior fonte de recursos para ações de transmidiação está na intertextualidade, que, de acordo com Bakhtin (1986), é o diálogo entre diferentes textos. As narrativas transmídia permitem a criação de um universo ficcional formado a partir de conteúdo distribuídos em várias plataformas midiáticas. Esta distribuição possibilita a expansão do conhecimento do sujeito sobre tal conteúdo, promovendo uma experiência de imersão. É a partir do desejo manifesto de ampliar a imersão que as franquias surgem, como uma extensão do conteúdo relacionado a um livro, filme, game, desenho animado, seriado ou história em quadrinhos (HQs).

De acordo com Carlos A. Scolari (2013, p. 45), há duas coordenadas para definir Transmídia: “1) expansão da estória através de várias mídias, e 2) colaboração dos usuários nesse processo de expansão". Ainda buscando elucidar o conceito de Transmídia, a partir da "Nova Teoria sobre Luz e Cores" de Isaac Newton (SILVA; MARTINS, 1996) é possível construir uma exemplificação imagética da experiência de imersão narrativa proporcionada pelas narrativas transmídia. Para tanto, estamos supondo que as plataformas midiáticas sejam as frações de um círculo cromático e suas cores, seus respectivos conteúdos. As cores são únicas, porém derivadas uma das outras; independentes, como os conteúdos transmidiáticos. Ao seguir a narrativa e lidar com estes conteúdos, o fã imerge na narrativa e tem uma

\footnotetext{
${ }^{1}$ Universidade de Brasília. Programa de Pós- Graduação em Educação.

${ }^{2}$ Faculdade Maurício de Nassau - Aracaju.
} 
possibilidade de conhecer de forma ampliada seu conteúdo. Esta condição ampliada é aqui demonstrada pelo uso da cor branca, a junção (do reflexo da luz) de todas as cores (como representada na Figura 1).

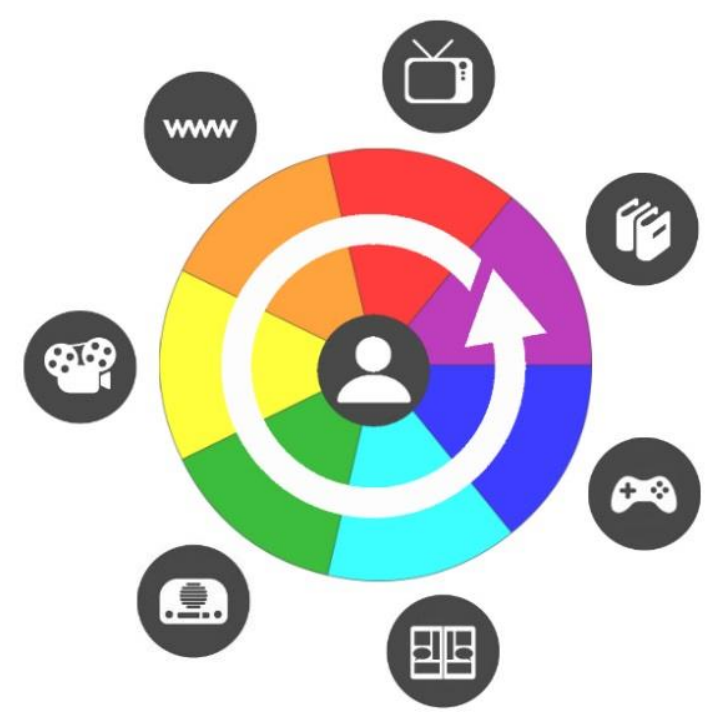

Figura 1 - Círculo cromático da experiência ampliada transmídia - Fonte: Desenvolvido pelo pesquisadores com base no círculo cromático de Isaac Newton.

Neste processo, cada mídia faz de maneira própria e específica sua contribuição para o desfecho, construindo uma experiência coordenada e unificada de entretenimento cujo significado é atribuído coletivamente (MARTINS, 2009). Por meio da representação imagética (Figura 1) da experiência proporcionada pelas narrativas transmídia, fica claro que os conteúdos transmidiáticos são desdobramentos uns dos outros, porém com suas particularidades.

Em suma, a narrativa transmídia atravessa diferentes mídias e com ela é possível criar um universo ficcional expandido ao redor da obra. Esta migração não é apenas uma migração de conteúdo, mas algo que requer um planejamento transmidiático atento a cinco principais elementos fundamentais (história, audiência, plataformas, modelo de negócio, execução) e que também prima por utilizar-se das potencialidades e recursos específicos de cada meio para ampliar a forma do sujeito lidar com o conteúdo ficcional exposto.

Destacamos como mais importante exercício de transmidiação ou desdobramento, a produção que é realizada pelos fãs ou seguidores (fanfics), em regime de coautoria, por meio da interação, da participação e da aprendizagem colaborativa. As fanfics são narrativas ficcionais criadas por fãs que utilizam personagens de um determinado produto cultural para criar suas próprias histórias e divulgá-las em sites e comunidades da internet sem fins lucrativos (VERSUTI; SILVA; LIMA, 2012).

Este tipo de escrita, ainda que ancorada no interesse por uma determinada narrativa original, possibilita resistências, fissuras e algumas linhas de fuga para um tipo de pensamento homogeneizador e capturado pelos interesses comerciais. Consideramos as fanfics como algo que "nada tem a ver com significar, mas com agrimensar, cartografar, mesmo que sejam regiões ainda por vir." (DELEUZE; GUATTARI, 1995, p. 19).

Isto porque, a noção de agenciamento para Deleuze e Guattari (1997), sugere certa insegurança sobre a possibilidade de descrever o funcionamento dos microdispositivos em termos de poder e resistência. Isto porque, nos sistemas sociais existem sempre linhas de fuga, 
bem como endurecimentos para impedir essas fugas, ou, aparelhos que as integram, desviam ou detém. Por ser nômade e molecular, a resistência não pode deixar de captar uma potência que é da ordem da criação e do movimento. Importante dizer que essas linhas de fugas não são revolucionárias por si, mas são justamente estas que os dispositivos de poder tentarão apreender, em um movimento de reterritorialização.

Consideramos que por ser potente, este tipo de escrita constantemente é utilizada pelos grandes conglomerados da indústria do entretenimento para servirem, novamente aos interesses comerciais. Neste texto, discutimos algumas possibilidades para os exercícios de transmidiação que podem se colocar como alternativas a este movimento de territorialização.

\section{As histórias em quadrinhos como potência para transmidiação}

As HQs representam mundialmente uma mídia de difusão de uma subcultura (HEBDIGE, 1998) em crescimento na contemporaneidade; a geek. Há títulos de HQs traduzidos para todos os idiomas e desdobramentos que vão do cinema à jogos de vídeo game.

Bryan Alexander (2011) diz que "a criação e consumo de histórias digitais é visto de uma forma atraente por estudantes digitalmente imersos." Para isto, o ideal é uma produto cultural estabelecido, com um personagem que já esteja inserido no referencial midiático dos sujeitos, integrar a cultura pop e que seja adaptável a novas plataformas ou passível de desdobramento narrativo por meio de fanfics.

Personagens como o Superman, da editora norte-americana DC Comics, fazem parte do referencial midiático mundializado (ORTIZ, 1994) e integram a cultura pop, estando presentes em várias plataformas midiáticas. A DC é uma das editoras mais antigas no segmento das HQs. Fundada nos Estados Unidos em 1934 (LEPORE, 2017), a editora tem entre seus personagens mais conhecidos Superman, Batman e Mulher-Maravilha, tendo sido a primeira a publicar quadrinhos no formato que conhecemos hoje, em revista. Ao longo de seus 83 anos de história, a DC Comics criou e incorporou ao seu catálogo centenas de personagens, fazendo uso constante de todos eles em muitas das mídias que produz, além das próprias revistas em quadrinhos.

Com o objetivo de poder (RE) significar todos os seus personagens, bem como os mundos que estes habitam, a DC criou seu Multiverso (Terras Paralelas), infinitos universos com suas próprias versões da Terra. Posteriormente, o Multiverso originou os Elseworlds; publicações da DC que narram histórias que se passam em universos paralelos onde podemos ver os personagens da editora em situações que não aconteceriam no em seus mundos originais. Em algumas histórias, os personagens são vistos em outros momentos históricos, como o Velho Oeste; em outras, futuros possíveis (geralmente trágicos) são mostrados.

Os Elseworlds ganham popularidade por apresentarem versões reimaginadas dos personagens e possuírem uma história curta, similar aos que fãs fazem com as fanfics. Por exemplo, "Superman: Entre a Foice e o Martelo" (Superman: Red Son) (MILLAR; JOHNSON; PLUNKETT, 2017), que mostra um mundo em que o Superman acaba caindo na União Soviética ainda bebê, tonando-se um herói e símbolo daquela nação. Apesar de não apresentar o herói tal como nas outras mídias, "Entre a Foice e o Martelo" conseguiu um enorme sucesso, inclusive na Rússia, antiga União Soviética (AGENCIA EFE, 2015).

Mesmo que, neste caso, o desdobramento diferenciado da narrativa original também tenha sido utilizado para atender à demandas de ordem do mercado e de sua reprodução, consideramos potente o uso das HQs, em especial as da DC, como base para exercícios de transmidiação e escrita criativa, visto que seus produtos possuem notório reconhecimento. 


\section{Aproximando transmidiação e educação}

Pensamos os exercícios de Transmidiação como ato de tradução de um sistema sígnico para outro que amplia as oportunidades de desenvolvimento para um pensamento gerador/gerativo e reflexivo, construindo conexões entre as diferentes linguagens e a criação de novas formas alternativas ao verbocentrismo praticado na educação formal, ou seja, compreendemos este esforço como prática de tradução intersemiótica para a transposição de conteúdos entre sistemas sígnicos distintos. Esta travessia entre sistemas sígnicos relaciona-se à capacidade de construção de metáforas e aplicação da função poética, que segundo as características dos signos, pode trazer em si, novas formas de representação e associações sonoras e visuais (SANTAELLA, 2013).

Em meio a este contexto hipermídia, marcado pelos conceitos de cibercultura e sua inserção em um ciberespaço cada vez mais diversificado, de interatividade e Narrativas Transmídia, temos a Educação, cada vez mais mediada por plataformas midiáticas. A Educação Colaborativa (CoLearning) pode ser encontrada ou aplicada em todos os segmentos educacionais, pois os princípios da imersão e do engajamento podem nos servir como dispositivos para a produção de desdobramentos narrativos criativos, produzidos pelos estudantes.

Se pensarmos que cada adaptação contendo um elemento narrativo original, ou cada desdobramento midiático do quadrinho para as outras mídias (ou o contrário) como sendo um Elseworld, o Multiverso DC seria uma potência para os exercícios de resistência dos fãs. Tal pressuposto remete à ideia que este exercício da transmidiação, justamente por utilizar as histórias originais como mediadoras estimulam a expansão/desdobramento e a criação de novas narrativas, implicando os seus autores num processo de atravessamento/tradução dos mundos ficcionais.

A participação dos fãs engajados na construção do conteúdo expandido é fundamental para a popularização e expansão da narrativa. Eles participam através da internet, criando blogs, páginas de redes sociais e fóruns e com esta partilha de opiniões e sugerem mudanças no curso da estória. Max Giovagnoli (2011) mostra que a criação de narrativas transmídia significa aceitar e ceder uma parte da autoria e responsabilidade da narrativa para outros narradores, a fim de criar novas estórias e experiências sinérgicas participativas. Para isto, o ideal é se basear em um produto cultural estabelecido, com um personagem que esteja inserido no referencial midiático dos sujeitos e que seja adaptável a novas plataformas ou passível de desdobramento narrativo por meio de fanfics.

Estes desdobramentos articulam-se em torno da disposição dos fãs ou seguidores na busca e associação de conteúdos adicionais em outras plataformas, estabelecendo novas relações de sentido em um formato de atuação que exige a cooperação direta dos novos elementos produzidos para que estes se completem, para que se realizem ou se concretizem (FECHINE et al., 2103).

Reiteramos assim que o elemento mais importante da transmidiação como escrita de resistência, são estas específicas produções, em que pese a possibilidade de um desdobramento pautado na colaboração e na coautoria, a despeito de se basearem em um produto cultural previamente encapsulado pelo universo simbólico do consumo e seu sistema sígnico.

\section{O voo do Superman}

Trazemos aqui alguns elementos que compuseram uma dissertação de mestrado em Educação, na qual foi estudado o desenvolvimento de transmidiação em uma disciplina on-line, utilizando uma narrativa originada em HQ. A proposta desenvolvida por esta pesquisa foi uma adaptação para fins de reflexão educativa da técnica denominada Super Heroes (VANGUNDY, 2005) utilizada na área da criatividade, com base nos conceitos de Narrativas Transmídia e 
dedicada para aplicação no ciberespaço. Tal técnica propõe que membros de grupos assumam a identidade de vários super-heróis e usem perspectivas dos personagens para incitar ideias. As adaptações feitas fizeram a técnica Super Heroes funcionar como dispositivo no exercício da expansão narrativa construída de forma colaborativa. Para isso, o professor precisou incentivar o engajamento dos estudantes por meio dos fóruns de discussão e aplicar a técnica (preferencialmente) em espaços abertos acessíveis por dispositivos móveis.

Dentre as vantagens de utilizar a Super Heroes em ambientes virtuais está a não necessidade de se trabalhar com a produção de imagens ou mídia mais elaboradas. Um filme, um desenho animado, um jogo, ou (como é o caso deste estudo) uma história em quadrinhos, pode ter sua narrativa expandida por meio de texto, uma ficção criada sem fins lucrativos como uma fanfiction.

Percebemos a transmidiação como a possibilidade de trazer outras escritas, motivadas por outros desejos, por novas configurações do pensamento que propõe o exercício de imaginar e criar outros desfechos e desdobramentos para as narrativas canonizadas, reconhecidas, repetidas e praticadas pelo senso comum, o que em última instância correspondem ao reforço de certas estruturas consolidadas de poder.

Para a implementação da proposta foi utilizada a graphic novel "Paz na Terra" (Peace on Earth) (1998) por Paul Dini (roteiro) e Alex Ross (roteiro e arte). No entanto, o contato dos estudantes mediado pelos professores com a narrativa no fórum foi feito apenas por meio de um resumo e de recortes (imagéticos e textuais), a partir dos quais o estudante poderia desenvolver uma estória fictícia do ponto de vista do personagem com base no conteúdo do curso.

Esta pesquisa foi desenvolvida entre 2013 e 2014, sendo o tema de uma dissertação de mestrado em Educação. O objetivo inicial da pesquisa contemplou a criação e aplicação de um objeto de aprendizagem virtual original com conceitos de Narrativa Transmídia. No decurso da investigação, com todos os desafios encontrados ao tentar atingir a proposta de investigação, uma pergunta tornou-se constate: é realmente possível construir uma relação prática entre Transmídia e Educação em uma instituição de ensino superior privada?

A disciplina on-line escolhida para esta pesquisa foi uma das quatro ofertadas em cursos presenciais de uma Instituição de Ensino Superior (IES), sendo a disciplina (ofertada na modalidade on-line) com a maior número de desistências. Seu objetivo é apresentar aos estudantes de graduação os fundamentos da antropologia e da sociologia.

Durante o primeiro ano de pesquisa, em parceria com os professores do curso, procuramos construir materiais pedagógicos virtuais com base nos principais conceitos de planejamento transmídia. Uma grande narrativa fragmentada, que consiste em hiperlinks, vídeos, podcasts e quiz.

Inicialmente realizamos uma pesquisa exploratória, a fim de melhor compreender a mitologia e história do personagem Superman, escolhido por encaixar-se no perfil descrito por Alexander (2011). Então roteiros, storyboards e esboços foram construídos. Ao acessar o objetivo virtual, o aluno poderia criar uma narrativa pessoal baseada no que aprendeu, estendendo o conteúdo do assunto por meio de uma história do Superman. Estas estórias seriam disponibilizadas em um repositório aberto licenciado. O material pré-elaborado apresentava um Superman pensativo, com menos ação e mais cenas mais reflexivas.

No entanto, para a produção de materiais de ensino com estas especificidades dentro de uma instituição privada foi necessário adquirir os direitos autorais do personagem. Mesmo para fins de pesquisa, apenas os estudantes inscritos no curso poderiam ter acesso ao material, caracterizando assim a venda de objeto virtual de aprendizagem. Desta forma, o custo elevado dos direitos de personagens levou à interrupção produção do material. Foi a maior implicação no método de desenvolvimento do objeto de investigação.

Entretanto, durante a criação de objeto virtual de aprendizagem, observou-se que é possível promover uma relação com a aprendizagem colaborativa. Isto porque foi preciso 
estudar o conteúdo do assunto, a fim de elaborar todo material em torno do conteúdo da disciplina e do personagem Superman. Assim, uma vez que o objeto foi abortado e não aplicado, para analisar as possibilidades educacionais de transmídia, esta pesquisa tomou um novo rumo: promover a co-criação de novas histórias e assim apostar no potencial de desdobramento das narrativas produzidas pelos estudantes do curso. Para isso, considerando as ferramentas tradicionais presentes no ambiente virtual, o fórum foi escolhido para desenvolver novos procedimentos de aplicação e análise.

Trabalhar com personagens sem fins lucrativos, não utilizando imagens e para fins de escrita criativa, é uma saída para utilizar obras preservadas por direitos autorais. Indica-se a utilização de referências de toda a mídia utilizada como base para a geração de novas estórias.

Conforme Cunha e Cruz et al. (2014, p. 70) a doutrina do fair use permite o acesso a obras disponíveis sem que seja necessário adquiri-las. Ainda segundo Cunha e Cruz et al., tal doutrina pode ser utilizada no que se refere ao uso de obras na Internet, "servindo para suprir uma lacuna legal que não é suficiente para regular os direitos autorais na era digital". Por meio do fair use é possível estudar, copiar, comentar, entre outros, uma obra protegida sem autorização expressa do autor da obra utilizada.

Dentre os recursos disponíveis para esta aplicação da técnica por meio do texto, o ambiente virtual da instituição disponibiliza o fórum: a partir de uma discussão iniciada pelo professor, os estudantes continuam através de comentários. O seguinte roteiro foi adotado para a aplicação:

a) Os estudantes tiveram contato com a história "Paz na Terra" por meio de um link que os levaram para um site que não possui caráter educacional, nem vínculo com esta pesquisa ou com a instituição de ensino;

b) O enunciado da atividade não possuiu mais que dois parágrafos de texto, na tentativa de ser claro e objetivo no que propunha;

c) Os estudantes não foram avisados de que a atividade compunha uma pesquisa de mestrado, nem sobre o que seria Narrativa Transmídia.

O texto usado para o exercício da expansão narrativa da história "Paz na Terra" é simples e direto, apresentando o personagem Superman como um produto cultural e também corroborando a técnica Super Heroes para apresentar as habilidades do personagem. Após acessar o link e promover uma breve imersão do aluno no universo ficcional, foi proposto que o aluno desenvolvesse uma história fictícia do ponto de vista do personagem com base no conteúdo do curso.

"Superman (ou Super-Homem) é um personagem das histórias em quadrinhos conhecido em todo mundo. Criado em 1938, o Homem de Aço, como também é conhecido, possui desenhos animados, jogos de vídeo game e até filmes com atores reais. Dentre suas aventuras mais aclamadas está "Paz Na Terra" (1999), cujo o resumo está no link a seguir: http://nerdpride.com.br/superman-e-a-paz-na-terral

Supondo que Superman fosse real e com suas habilidades (visão de raio-x, super audição, voo, super força e hiper velocidade) pudesse resolver problemas da nossa sociedade (como em "Paz Na Terra"), com base no conteúdo e as discussões da Parte 2 desta disciplina, desenvolva uma pequena história ficcional (FIC) narrando esta aventura.

É fundamental destacar que todas as interações realizadas por professores e estudantes foram, de fato, voluntárias. Consideramos que estas produções voluntárias, produzidas pela espontaneidade é que são as efetivamente potentes do ponto de vista da transmidiação enquanto 
escrita de resistência, pois estas revelam uma articulação que extrapola os objetivos previamente definidos pela atividade no ambiente virtual de aprendizagem institucional e apontam para fissuras, questionamentos, desdobramentos mais soltos e menos aprisionados. Mais relevante que cumprir a tarefa proposta, o desejo de produzir uma narrativa nova de maneira articulada e colaborativa foi o principal resultado desta experiência de coaprendizagem e coautoria (OKADA, 2014).

\section{Desdobramentos}

Segundo Sharda $(2009$, p. 2) a potencialidade de trabalhar com a transmidiação reside na possibilidade de articular os conteúdos pedagógicos com atividades que já estão presentes no cotidiano dos estudantes, tal como o trabalho colaborativo, o compartilhamento de informações e a interação. Pensamos assim que o uso destes recursos abertos pode auxiliar os educadores no desenvolvimento de práticas capazes de melhor atender às demandas dos alunos, justamente por adaptarem-se ao seu contexto, considerando também os vários estágios de aprendizagem dos estudantes, suas particularidades e interesses.

Os encaminhamentos finais deste texto discutem como a proposição de exercícios de transmidiação podem possibilitar o desenvolvimento de materiais nos moldes da Educação Aberta. Para isso, detalharemos o conceito de aprendizagem colaborativa, também conhecida como Coaprendizagem ou Colearning.

De acordo com Okada (2014), a Web 2.0 proporciona o aumento do uso de recursos educacionais mais flexíveis (como os de licença aberta, por exemplo), que oferece maiores oportunidades para a reutilização e reconstrução do conhecimento, de forma colaborativa, e desta forma, novos coautorias. Ainda segundo a autora, foi após o advento da Web 2.0 que a coaprendizagem conquistou relevância devido "a criação e troca de conhecimentos produzidos por usuários e informações compartilhadas rapidamente" (OKADA, 2014, p. 98).

Em Co-learning, todos se tornam parceiros no "processo de aprendizagem colaborativa, na construção de significados e criação de conhecimento em conjunto" (OKADA 2014, p. 97). Diferente do que é oferecido pela educação on-line ou e-learning, o conteúdo não é responsabilidade única da instituição, que, como visto neste estudo, atribui a autoria apenas para professores em uma obra sem distribuição ou reprodução permitidas.

Por sua vez, o termo educação aberta é empregado em diversos contextos e diz respeito desde práticas mais tradicionais até outras mais recentes, podendo não fazer uso exclusivo de Recursos Educacionais Abertos (REA). "A utilização de recursos educacionais abertos é mais uma maneira de se fazer educação aberta" (SANTOS, 2012, p. 71).

Faz-se então necessário compreender que, promover tal abertura na educação dentro do ciberespaço é fazer uso de uma série de novas propostas que garantam ao estudante maior acessibilidade à educação. Os REA, tal como definidos pela Unesco (2011), são "materiais de ensino, aprendizado e pesquisa em qualquer suporte ou mídia, que estão sob domínio público, ou estão licenciados de maneira aberta, permitindo que sejam utilizados ou adaptados por terceiros". Em suma, um recurso de livre acesso e edição, podendo ser remixado e disponibilizado para que este processo continue a se repetir na rede.

A educação aberta possui um conjunto de práticas que a caracteriza, estas carregam aspectos exclusivos a depender do contexto. Tais práticas estão pautadas nos itens a seguir:

a liberdade do estudante decidir onde estudar, podendo ser de sua casa, do seu trabalho ou até mesmo da própria instituição de ensino e/ou polos de aprendizagem; 
- a possibilidade de se estudar por módulos, acúmulo de créditos ou qualquer forma que permita ao estudante aprender de forma compatível com o ritmo necessário para seu estilo de vida;

- a utilização da autoinstrução, com reconhecimento formal ou informal da aprendizagem por meio de certificação opcional;

- a isenção de taxas de matrícula, mensalidades e outros custos que seriam considerados uma barreira ao acesso à educação formal;

- a acessibilidade dos cursos para estudantes portadores de alguma deficiência física, bem como dos que têm alguma desvantagem social;

- a provisão de recursos educacionais abertos, utilizados tanto na educação formal quanto na informal (SANTOS, 2012, p. 72).

Os novos conteúdos produzidos dentro desta perspectiva, tal como as narrativas dos estudantes desta investigação, podem ter licenças abertas, como o Creative Commons. Por meio das licenças abertas, esses objetos têm agora maior flexibilidade, permitindo oportunidades para criação e compartilhamento de materiais na rede, como por exemplo, um blog ou site, externos ao ambiente virtual de aprendizagem. Há vários tipos de licença, desde as mais abertas às mais fechadas, o autor é que deve escolher qual a forma adequada para disponibilizar e circular seu contéudo produzido, preservando sua autoria (CUNHA E CRUZ, et. al, 20014).

Considerar intervenções e propostas como estas pode ser uma possibilidade de potencializar a educação online, abrindo novos caminhos para novas formas e concepções de escrita e potentes exercícios de pensamento e de criação.

Na realidade, enquanto se inscreve a diferença no conceito em geral, não se tem nenhuma Idéia singular da diferença, permanecendo-se apenas no elemento de uma diferença já mediatizada pela representação. Encontramonos, pois, diante de duas questões: qual é o conceito da diferença - que não se reduz à simples diferença conceitual, mas que exige uma Idéia própria, como uma singularidade na Idéia? Qual é, por outro lado, a essência da repetição que não se reduz a uma diferença sem conceito, que não se confunde com o caráter aparente dos objetos representados sob um mesmo conceito, mas que, por sua vez, dá testemunho da singularidade como potência da Idéia? O encontro das duas noções, diferença e repetição, não pode ser suposto desde o início, mas deve aparecer graças a interferências e cruzamentos entre estas duas linhas concernentes, uma, à essência da repetição, a outra à idéia de diferença." (DELEUZE, 1988, p. 61).

Sendo assim, compreendemos a transmidiação como uma forma de trazer escritas diferenciadas, motivadas por desejos, por novas configurações de coautoria (OKADA, 2014) que propõem o exercício de imaginar, de criar colaborativamente alguns desdobramentos e outros desfechos para narrativas canonizadas reconhecidas e reiteradas pelo senso comum, que em última instância correspondem à ordem da diferenciação, da intensidade e não da repetição.

\section{Referências}

AGENCIA EFE. "Superman vermelho" se torna um sucesso de vendas na Rússia. 2015. Disponível em: <http://g1.globo.com/pop-arte/noticia/2015/01/superman-vermelho-se-tornaum-sucesso-de-vendas-na-russia.html>. Acesso em: 8 de nov. 2017. 
ALEXANDER, Bryan. The New Digital Storytelling: creating narratives with new media. Santa Barbara: PRAEGER, 2011.

BAKHTIN, Mikhail. Marxismo e Filosofia da Linguagem. 3 Ed. São Paulo: Editora Hucitec, 1986.

BAUMAN, Zygmunt. Modernidade Líquida. Rio de Janeiro: Zahar, 2003.

CUNHA E CRUZ, Marco Aurélio R. de; et al. Reflexões sobre a relação entre Direito Autoral, Creative Commons e Narrativas Transmídia. In: VERSUTI, Andrea C.; BERALDO, Rossana; GOSCIOLA, Vicente (Org.). Formação de professores: trasmídia, conhecimento e criatividade. Recife: Editora UFPE, 2014. p. 55 - 82.

DELEUZE, Gilles. Diferença e Repetição. Tradução: Luiz Orlandi, Roberto Machado. Rio de Janeiro: Graal, 1988.

DELEUZE, Gilles; GUATTARI, Félix. Mil platôs: capitalismo e esquizofrenia. v. 1. Tradução de Aurélio Guerra Neto e Célia Pinto Costa. Rio de janeiro: Ed. 34, 1995a.

DELEUZE, Gilles; GUATTARI, Félix. Mil platôs: capitalismo e esquizofrenia. Tradução de Aurélio Guerra Neto e Célia Pinto Costa Rio de Janeiro: Editora 34, 1997.

FECHINE, Yvana et al. Como pensar os conteúdos transmídias na teledramaturgia brasileira? Uma proposta de abordagem a partir das telenovelas da Globo. In: LOPES, Maria I. V. de (Org.). Estratégias de transmidiação na ficção televisiva brasileira. Porto Alegre: Sulina, 2013.

FOX, Gardner; INFANTINO, Carmine. The Flash 123. In: MORRISON, Grant; QUITELY, Frank. LJA: Terra 2. 13 ed. São Paulo: Eaglemoss, 2015. p. 114 -140.

GIOVAGNOLI, Max. Transmedia Storytelling: imagery, shapes and techniques. Pittsburgh: ETC Press, 2011.

HEBDIGE, Dick. Subculture: the meaning of style. Nova York: Routledge, 1998.

JENKINS, Henry. Convergence Culture. New York: NYU Press, 2008.

LEMOS, André. Cibercultura como território recombinante. In: TRIVINHO, Eugênio; CAZELOTO, Edilson. A cibercultura e seu espelho: campo de conhecimento emergente e nova vivência humana na era da imersão interativa. São Paulo: ABCiber; Instituto Itaú Cultural, 2009.

LEPORE, Jill. A História Secreta da Mulher-Maravilha. Tradução Érico Assis. 1. ed. Rio de Janeiro: BestSeller, 2017.

MARTINS, Cecília. A cultura da convergência e a narrativa transmídia. 2009. Disponível em: $<$ http://opiniaoenoticia.com.br/vida/tecnologia/a-cultura-da-convergencia-e-a-narrativatransmidia/>. Acesso em: 8 de out. 2017.

MILLAR, Mark; JOHNSON, Dave; PLUNKETT, Killian. Superman: entre a foice e o martelo. Tradução Jotapê Martins. Barueri: Panini Brasil, 2017. 
OKADA, Alexandra. Espaços e (co)relações de conhecimento para coaprender e coinvestigar em rede. In: LINHARES, Ronaldo N.; PORTO, Cristiane; FREIRE, Valéria (Org.). Mídia e educação: espaços e (co) relações de conhecimentos. Aracaju: EDUNIT, 2014. p. 97-120.

ORTIZ, Renato. Mundialização e Cultura. SP: Brasiliense, 1994.

ROSS, Alex; DINI, Paul. Super-Homem: Paz na Terra. São Paulo: Abril, 1999.

SANTAELLA, Lucia. Cultura das mídias. São Paulo: Experimento, 1996.

SANTAELLA, Lucia. Matrizes da Linguagem e Pensamento: sonora, visual, verbal. 3 ed. São Paulo: Iluminuras, 2013.

SANTOS, Andrea I. Educação aberta histórico, práticas e o contexto dos recursos educacionais abertos. In: Recursos Educacionais Abertos: práticas colaborativas e políticas públicas. SANTANA, Bianca; ROSSINI, Carolina; PRETTO, Nelson de L. (Org.). Salvador: EDUFBA, 2012. p. 71-90.

SCOLARI, Carlos A. Narrativas Transmedia: Cuando todos los medios cuentan. Barcelona: Deusto S. A. Ediciones, 2013.

SHARDA, Nalin. Using Storytelling as the Pedagogical Model for Web-Based Learning in Communities of Practice. In: KARACAPILIDIS, N. (ed.). Web-Based Learning Solutions for Communities of Practice: Developing Virtual Environments for Social and Pedagogical Advancement. Pratas: University of Patras, 2009.

SILVA, Cibelle C.; MARTINS, Roberto A. A "Nova Teoria sobre Luz e Cores" de Isaac Newton: uma tradução comentada. Revista Brasileira de Ensino de Física. s. 1., v. 18, n. 4, p. 313-327, dez. 1996.

UNESCO. UNESCO and education: "Everyone has the right to education". UNESCO, Paris, 2011.

VANGOUNDY, Arthur B. 101 Activities for Teaching Creativity and Problem Solving. São Francisco: Pfeiffer, 2005.

VERSUTI, Andrea; SILVA, Daniel D. A. da; LIMA, Daniella de J. O potencial transmidiático de Harry Potter e suas fanfictions. In: CAMPALANS, Carolina; RENÓ, Denis; GOSCIOLA, Vicente (Org.). Narrativas Transmedia: entre teorías y practices. Bogotá: Editorial Universidad del Rosario, 2012. 